\title{
Woody Species Colonization along Edge-Interior Gradients of Deciduous Forest Remnants in the Mae Khum Mee Watershed, Northern Thailand
}

\author{
Lamthai Asanok $\mathbb{D}^{1},{ }^{1}$ Rungrawee Taweesuk, ${ }^{2}$ and Nitpavaridsa Papakjan ${ }^{3}$ \\ ${ }^{1}$ Department of Agroforestry, Maejo University, Phrae Campus, Phrae 54140, Thailand \\ ${ }^{2}$ Department of Forest Management, Maejo University, Phrae Campus, Phrae 54140, Thailand \\ ${ }^{3}$ Highland Research and Development Institute (Public Organization), Chiang Mai 50200, Thailand
}

Correspondence should be addressed to Lamthai Asanok; lamthainii@gmail.com

Received 31 October 2019; Revised 9 January 2020; Accepted 4 February 2020; Published 7 March 2020

Academic Editor: Daniel M. Kashian

Copyright (C) 2020 Lamthai Asanok et al. This is an open access article distributed under the Creative Commons Attribution License, which permits unrestricted use, distribution, and reproduction in any medium, provided the original work is properly cited.

\begin{abstract}
This study investigated the environmental factors and tree species characteristics that are important for the colonization of edgeinterior gradients, for later application to the restoration of edge-transition areas created by highland agriculture in deciduous forests in the Mae Khum Mee watershed, northwest Thailand. Three belt plots $(100 \times 10 \mathrm{~m})$ were established at the transition from the forest edge to the interior of two deciduous forest types (mixed deciduous forest [MDF] and deciduous dipterocarp forest $[D D F])$, for a total of six belt plots. The species composition of canopy trees and regenerated seedlings and saplings was assessed, together with several environmental factors. We analyzed the relative importance of the physical environment and recruitment limitation was evaluated in relation to the regeneration traits of tree species. The results indicated that it was difficult for DDF and MDF species to effectively colonize the near-edge areas of the forests, primarily because the key factors related to seedling and sapling colonization (i.e., recruitment limitation, the physical environment, and factors related to forest structure) did not match the edge environment. Generalist species experienced much less recruitment limitation along the edge-interior gradients of both DDFs and MDFs. Generalists such as Pterocarpus macrocarpus, Dalbergia cultrata, and Vitex pinnata exhibited more successful establishment under conditions at the edges of both deciduous forests. These findings suggest that the natural regeneration of generalist species can be utilized as a first step in forest-edge restoration due to their facilitation of subsequent colonization by primary forest species.
\end{abstract}

\section{Introduction}

Deciduous forests grow in regions that experience several months of severe drought each year and these can cover large tropical and subtropical landscapes [1]. Mixed deciduous forest (MDF) and deciduous dipterocarp forest (DDF) are types of deciduous forest found in Thailand $[2,3]$. These forests have a long history of disturbance from frequent fires and human activities [4]. Specifically, slash-and-burn agriculture is causing the decline and fragmentation of DDF and MDF ecosystems throughout Thailand [5]. These agricultural strategies result in mosaics of agricultural land and forest remnants [6]. Fragmentation and reductions in the area of forest have caused a severe loss of biological diversity [7].

Forest edges caused by fragmentation serve as the dividing line between edge-interior and edge-exterior areas. The vegetative structure and species composition differ between the interior and exterior of the forest edge [8]; such differences are exacerbated by increasing fragmentation [9]. Edge effects sometimes manifest as reductions in canopy height and increases in subcanopy stature from the forest interior towards the edge [10]. However, forest edges may play an important role in the restoration of forests and much more information on the interior-edge vegetation and tree regeneration is required 
[8]. The edge-interior environment is unsubstantial, especially when abrupt transitions occur between vegetation communities with distinct structures and compositions [11]. Environments around the edge may provide crucial colonization sites within fragmented landscapes, while aggregated forests are sufficiently buffered for maintaining species that are sensitive to environmental changes [12]. The recruitment limitation is also important at edge sites and may increase or decrease the chances of plant establishment according to the mechanisms of seed and site limitation [13]. Previous studies suggested that the distance from the edge to the interior of the forest, and microenvironment, may affect seedling recruitment and forest structure $[10-12,14]$.

In northern Thailand, most watershed areas are covered by deciduous forests (including MDF and DDF). This forested land has been affected by a long history of permanent cropping and crop-fallow cycles [15]. Consequently, the extent of the forest edge also increases due to such scattered forest patches in watershed areas. Forest edges in the vicinity of head watershed areas are now in urgent need of restoration for biodiversity conservation. Therefore, this study examined how environmental factors are linked to woody species colonization along edge-interior gradients in the Mae Khum Mee watershed, Phrae Province, northern Thailand. Our primary objective was to elucidate key ecological processes to inform necessary improvements in forest-edge management. We focused on determining which environment factors and recruitment limitations most strongly affect woody tree species colonization within the edge habitats of MDF and DDF.

\section{Materials and Methods}

2.1. Study Area. The study was conducted along the edgeinterior gradient (i.e., transition from the edge into the forest interior) of seasonally dry deciduous forest remnants in the Mae Khum Mee subwatershed area. This region covers $452.4 \mathrm{~km}^{2}$ of Phrae Province, northern Thailand $\left(18^{\circ} 22^{\prime}-18^{\circ} 28^{\prime} \mathrm{N}, 100^{\circ} 08^{\prime}-100^{\circ} 33^{\prime} \mathrm{E}\right.$; Figure 1), and the site spans elevations of $320-540 \mathrm{~m}$ above mean sea level. The mean annual temperature and rainfall are $26.5^{\circ} \mathrm{C}$ and $1200 \mathrm{~mm}$, respectively. The region experiences two main seasons: (i) wet (May-October; mean rainfall and temperature of $1460 \mathrm{~mm}$ and $35.42^{\circ} \mathrm{C}$, respectively) and (ii) dry (November-April; mean rainfall and temperature of $406 \mathrm{~mm}$ and $35.42^{\circ} \mathrm{C}$, respectively). The dry season is subdivided into cool-dry (November-January) and hotdry subseasons (February-April). The main original vegetation type in the Mae Khum Mee watershed is deciduous forest of two types: DDF and MDF. Several large remnant patches of relatively undisturbed forest remain in the head watershed area of this region. Forest fragmentation has been caused by highland agriculture, which involves cultivating maize after slash-and-burn clearing of forests, thus generating the scattered distribution of remnant forest patches throughout the watershed [16]. The study sites regularly experience wildfires during the dry season, caused by farmers burning corn stumps after harvest $[17,18]$.
2.2. Sampling Plot Selection and Data Collection. This study collected data from January to December 2017. We selected DDF and MDF edge sites in similar topographic areas, e.g., altitudes of 400 above mean sea level, on a $45 \%$ slope, and about $5 \mathrm{~km}$ from a village. At all of the edge sites, maize had been cultivated in the fields before abandonment 3 years earlier, as confirmed by interviews with the local residents.

Within each DDF and MDF edge site, we established three $10 \times 100 \mathrm{~m}$ belt plots for each forest type, for six belt plots in total. The belt plots clearly incorporated the edge zone, such that the species composition reflected the edge effect [8]. The forest edge is the line separating the interior and exterior of the forest, and the structure and species composition differ between the interior (i.e., dense mature trees) and exterior (i.e., sparse shrubs/juveniles or bare land) parts [19]. Several studies have noted that the edge coincides with the bases of bordering mature forest tree trunks $[19,20]$. Each belt plot ran from the forest edge to the interior for $100 \mathrm{~m}$ and was perpendicular to the edge line; the first plot was located near the first mature tree at the edge line (Figure 2). Each $10 \times 100 \mathrm{~m}$ belt plot was subdivided into 10 adjacent $10 \times 10 \mathrm{~m}$ plots, generating 30 plots per forest type or 60 plots $(0.6 \mathrm{ha})$ in total.

We enumerated all mature trees $(\geq 1.3 \mathrm{~m}$ height, with diameter at breast height $[\mathrm{DBH}] \geq 4.5 \mathrm{~cm}$ ) and saplings $(\mathrm{DBH}<4.5 \mathrm{~cm}$, but height $>1.30 \mathrm{~m})$ in the $10 \times 10 \mathrm{~m}$ plots. In the lower left corner of every $10 \times 10 \mathrm{~m}$ plot, we established $4 \times 4 \mathrm{~m}$ subplots, for a total of 10 subplots per $10 \times 100 \mathrm{~m}$ belt plot (Figure 2). Within these subplots, tree seedlings (height $<1.30 \mathrm{~m}$ ) were enumerated. Diameter at breast height was measured at $1.3 \mathrm{~m}$ height for all mature trees but we only counted the number of saplings and seedlings of each species. All trees, saplings, and seedlings were identified to species by collecting specimens and comparing them to standard specimens in the herbarium of the National Park, Wildlife and Plant Conservation, Thailand. The nomenclature followed Pooma and Suddee [21].

2.3. Measurements of Environmental Factors. The environmental variables soil moisture content (SMC; \%), soil bulk density ( $\left.\mathrm{SDb} ; \mathrm{g} \mathrm{cm}^{-3}\right)$, and photosynthetically active radiation (PAR; $\mu \mathrm{mol}$ photons $\mathrm{m}^{-2} \mathrm{~s}^{-1}$ ) were measured in each $10 \times 10 \mathrm{~m}$ plot, for 60 plots in total. The average SMC and SDb per plot were measured at the four corners and in the center of each $10 \times 10 \mathrm{~m}$ plot in October 2017. Using a soil core sampler with a volume of $100 \mathrm{~cm}^{3}$, soil was collected from the top soil layer at $0-15 \mathrm{~cm}$ depth. All soil samples were collected on the same day, 10 days after the last rain. This time of year is close to the beginning of the dry season in this area, with infrequent rain but still relatively humid soil. Soil conditions during this time period will likely better reflect the variation among quadrats than those during the mid-rainy or mid-dry seasons. The SDb was estimated for each soil sample as the proportion of mass of oven-dried soil to the total volume. The SMC was determined as the ratio of fresh weight to dry weight. We also measured PAR ( $\mu \mathrm{mol}$ photons $\mathrm{m}^{-2} \mathrm{~s}^{-1}$ ), which measures photon flux within the $400-700-\mathrm{nm}$ spectral band of solar radiation. The average PAR values per plot were also measured in the four corners 


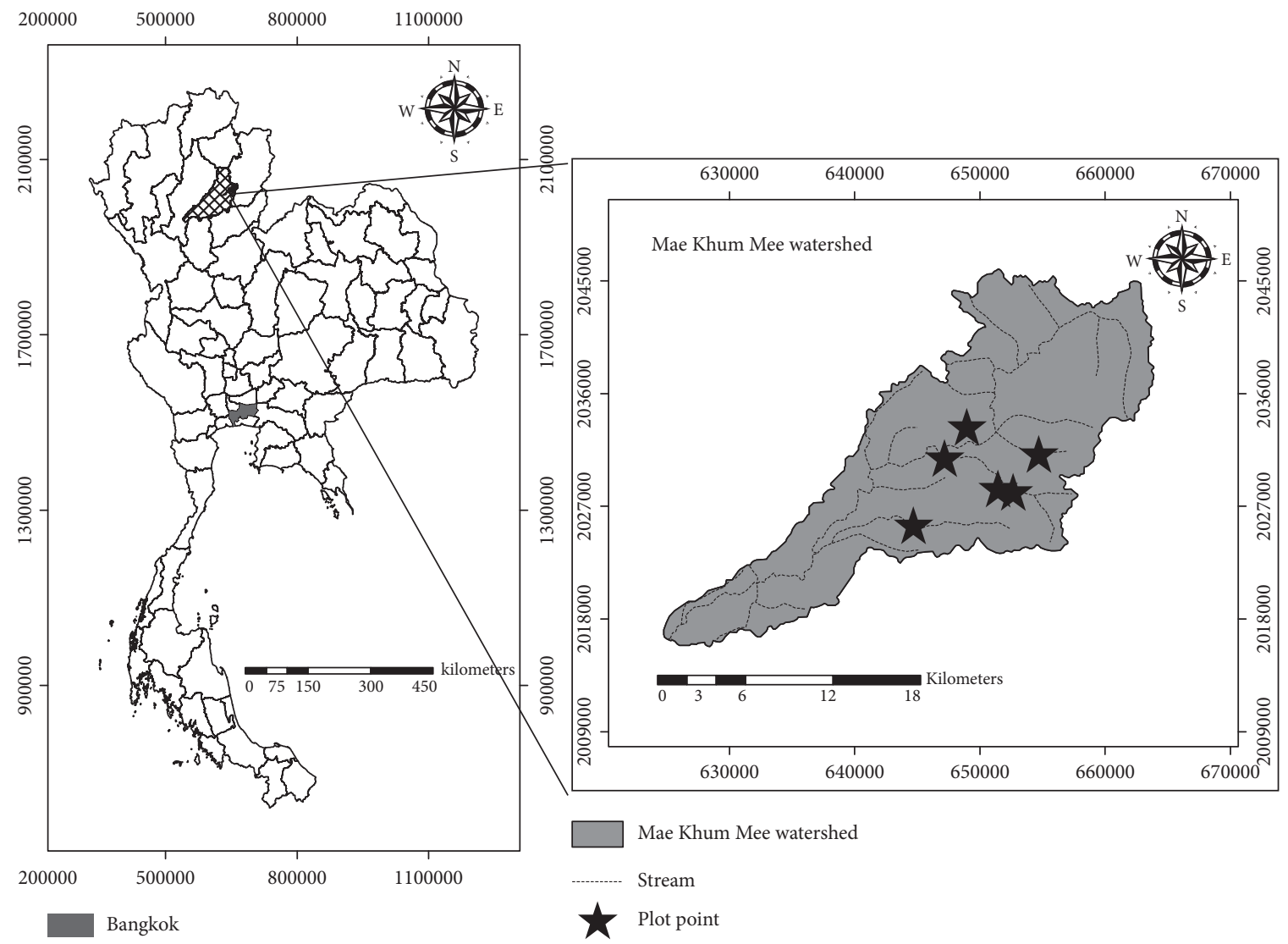

Phrae

Mae Khum Mee watershed

Figure 1: Locations of the Mae Khum Mee subwatershed and study sites in Phrae Province, northern Thailand.

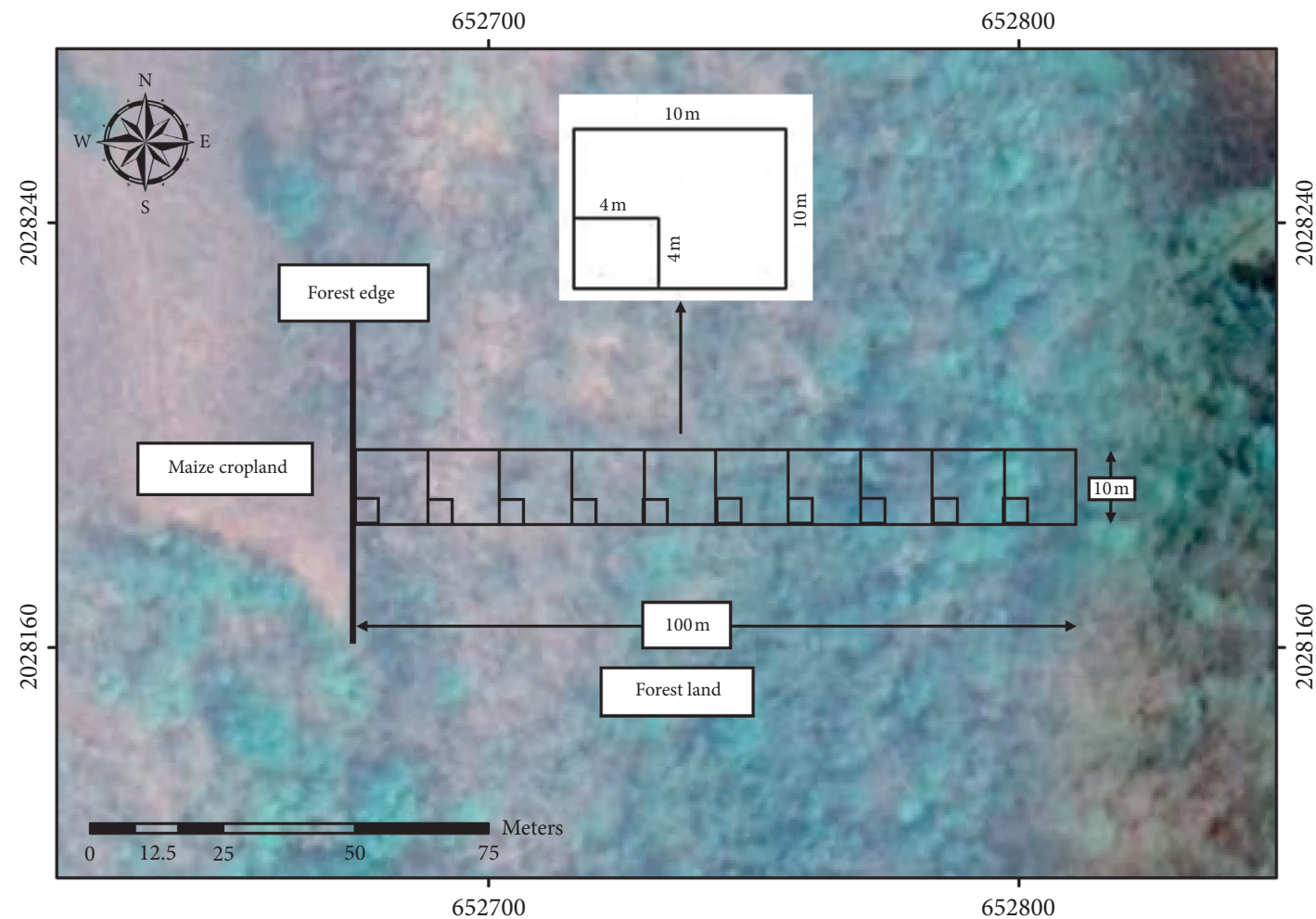

Figure 2: Belt plots $(10 \times 100 \mathrm{~m})$ were established in a deciduous dipterocarp forest (DDF) and a mixed deciduous forest (MDF) at the transition point from the edge to the interior of the forest in the Mae Khum Mee subwatershed, Phrae Province. 
and at the center in each of $10 \times 10 \mathrm{~m}$ plot, using a Spectrum 3415FX LightScout External Sensor. Each measurement was made $1.3 \mathrm{~m}$ above ground level on a sunny day (08:00-10:00) in November 2017. The parameters SMC, SDb, and PAR were used to analyze mature trees, seedlings, and saplings in both the $10 \times 10 \mathrm{~m}$ plots and $4 \times 4 \mathrm{~m}$ subplots.

2.4. Statistical Analyses. We used the $t$-test to compare the differences in physical factors (SMC, SDb, and PAR) between the DDF and MDF edges. For the overall comparison, we analyzed data from all plots in each forest type $(n=30$ per forest type) and compared those at each $10 \mathrm{~m}$ distance along the $100 \mathrm{~m}$ line from the edge to the interior of the forest against the data from the $10 \times 10 \mathrm{~m}$ plots located every $10 \mathrm{~m}$ from the edge in each forest type ( $n=3$ per forest type). A graph of the data along the $100 \mathrm{~m}$ line from the forest edge was plotted. To investigate the constancy of the colonization of woody species in each forest edge type, we classified the woody species into DDF species, MDF species, or generalist species; we used the Mann-Whitney $U$ test to analyze the mature tree stem density (TD; per 0.01 ha plot) for the 30 samples from each of the DDF and MDF sites. Species were grouped into (1) DDF species that had a significantly high density in DDFs; (2) MDF species with a significantly high density in MDFs; (3) generalist species without any significant density bias (i.e., species that can become established in both DDF and MDF edge sites); and (4) infrequent species with inadequate densities for statistical analysis. We analyzed regeneration characteristics using the number of seedlings (in the $4 \times 4 \mathrm{~m}$ subquadrats) and saplings (in the $10 \times 10 \mathrm{~m}$ quadrats) of each species from subplots located at the same position at each edge site, for a total of 30 samples for each DDF and MDF site. We also applied the Mann-Whitney $U$ test to analyze sapling and seedling densities in the DDFs and MDFs.

To investigate which physical and recruitment limitation factors (i.e., distance from the edge to the interior) affected mature tree abundance in each forest type (DDF and MDF), we analyzed matrices of (1) adult tree stem densities in the $10 \times 10 \mathrm{~m}$ quadrats and (2) the physical variables $(\mathrm{SMC}, \mathrm{SDb}$, and PAR) and distance from the edge to the forest interior (Dis; $\mathrm{m})$ using nonmetric multidimensional scaling (NMS) ordination with PC-ORD for Windows (ver. 6; MjM Software, Gleneden Beach, OR, USA). A Monte Carlo permutation test was performed with 999 permutations to assess the statistical significance of each factor variable within the NMS ordination, to determine whether NMS was extracting stronger axes than expected by chance [22]. The Monte Carlo permutation test was constructed using the vegan package in $\mathrm{R}$ ver. 3.4.2.

We also used $\mathrm{R}$ ver. 3.4.2 to analyze factors affecting regeneration; we applied generalized linear mixed models (GLMMs) in a stepwise regression analysis for seedling and sapling densities of species with sufficient density for statistical analyses (i.e., species with $\geq 30$ stems). The independent variables were (1) the physical environmental factors PAR ( $\mu$ mol photons $\mathrm{m}^{-2} \mathrm{~s}^{-1}$ ), SMC (\%), and SDb $\left(\mathrm{g} \mathrm{cm}^{-3}\right)$; (2) forest structure variables, i.e., basal area (BA, $\left.\mathrm{m}^{2} \mathrm{ha}^{-1}\right)$, and mature tree density (TD, stem ha $\left.{ }^{-1}\right)$; and (3) factors related to recruitment limitation (seed and site limitation), i.e., Dis (m) and conspecific adult density (CD, stem $0.01 \mathrm{ha}^{-1}$ ). All factors had correlation coefficients less than 0.7 . The plot site was included as a random factor, and the model with the lowest Akaike's information criterion (AIC) was selected for each species [23].

\section{Results}

3.1. Environmental Factors along the Edge-Interior Gradient. Overall, the three physical factors (SMC, SDb, and PAR) differed between the forest edge types (DDF vs. MDF; Table 1). The PAR in the DDF edge was significantly higher than in the MDF $(424.37 \pm 78.77$ vs. $91.90 \pm 14.17 \mu \mathrm{mol}$ photons $\mathrm{m}^{-2} \mathrm{~s}^{-1}$, respectively; $\left.p<0.01\right)$. The SDb in the DDF edge was also significantly higher than in the MDF edge $\left(1.15 \pm 0.10\right.$ vs. $0.94 \pm 0.07 \mathrm{~g} \mathrm{~cm}^{-3}$, respectively; $\left.p<0.05\right)$. By contrast, the SMC in the MDF edge was significantly higher than in the DDF edge $(36.92 \pm 4.66 \%$ vs. $26.46 \pm 7.12 \%$, respectively; $p<0.05)$. Comparing the edges of the two forest types along the $100 \mathrm{~m}$ from the edge into the forest, there were no significant differences in the three physical factors near the edge (i.e., 10 or $20 \mathrm{~m}$ from the edge). However, as the distance from the edge to the forest interior increased, the differences between PAR and SDb in the two forest types were significant $(p<0.05)$. The factor SMC showed a similar trend in the two forest types (Table 1). PAR tended to change the most when the distance from the edge to the interior of the forest was up to $50 \mathrm{~m}$; the difference in PAR between the two forest types increased steadily with distance (Figure 3(a)). SDb in the DDF was significantly higher than the MDF along the entire 100-m edge-interior gradient (Figure 3(b)). By contrast, SMC was significantly higher in the MDF than in the DDF along the entire edge-interior gradient (Figure 3(c)).

3.2. Woody Species Composition. In total, mature trees comprised 2,745 stems of 114 species, 80 genera, and 34 families. The dominant species in the DDF included Shorea obtusa, Shorea siamensis, Dipterocarpus obtusifolius, Mitragyna rotundifolia, Lannea coromandelica, Aporosa nigricans, Dalbergia oliveri, Strychnos nux-vomica, Terminalia chebula, and Buchanania lanzan (Table 2). The dominant species in the MDF were Phanera bracteata, Xylia xylocarpa, Schleichera oleosa, Millettia brandisiana, Vitex canescens, Tectona grandis, Dalbergia nigrescens, Croton poilanei, Hymenodictyon orixense, Naringi crenulata, and Kydia calycina. The dominant generalist species included Pterocarpus macrocarpus, Vitex pinnata, Dalbergia cultrata, Colona flagrocarpa, Canarium subulatum, and Terminalia alata. Based on abundance, we categorized a total of $17 \mathrm{DDF}$ species, $11 \mathrm{MDF}$ species, and six generalist species (Table 2). All other species were classified as infrequent species.

3.3. Regeneration of Seedlings and Saplings. Twelve of seventeen DDF species were able to regenerate along the edge of the DDF. In particular, Shorea obtusa and Aporosa nigricans exhibited the highest abundances at the DDF sites. Most tree 


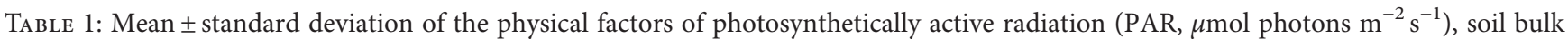
density $\left(\mathrm{SDb}, \mathrm{g} \mathrm{cm}^{-3}\right.$ ), and soil moisture content (SMC, \%), as measured in each $10 \times 10 \mathrm{~m}$ plot along the $100 \mathrm{~m}$ line from the edge to the forest interior (Dis).

\begin{tabular}{|c|c|c|c|c|c|c|c|c|c|}
\hline \multirow{2}{*}{ Dis } & \multicolumn{3}{|c|}{ PAR } & \multicolumn{3}{|c|}{$\mathrm{SDb}$} & \multicolumn{3}{|c|}{ SMC } \\
\hline & DDF & MDF & Sig. & DDF & MDF & Sig. & DDF & MDF & Sig. \\
\hline 10 & $177.33 \pm 27.23$ & $122.46 \pm 90.09$ & NS & $1.13 \pm 0.06$ & $1.04 \pm 0.05$ & NS & $28.70 \pm 5.67$ & $35.55 \pm 0.68$ & NS \\
\hline 20 & $212.26 \pm 56.21$ & $80.53 \pm 35.25$ & $*$ & $1.15 \pm 0.08$ & $0.96 \pm 0.05$ & NS & $26.23 \pm 8.92$ & $38.92 \pm 0.50$ & $*$ \\
\hline 30 & $350.80 \pm 74.17$ & $76.06 \pm 46.39$ & $*$ & $1.19 \pm 0.06$ & $0.91 \pm 0.07$ & $*$ & $24.65 \pm 4.76$ & $38.45 \pm 1.71$ & $*$ \\
\hline 40 & $350.26 \pm 32.83$ & $77.93 \pm 33.82$ & * & $1.16 \pm 0.06$ & $0.98 \pm 0.03$ & $*$ & $29.52 \pm 6.17$ & $36.36 \pm 1.06$ & NS \\
\hline 50 & $343.80 \pm 69.74$ & $80.06 \pm 54.52$ & $*$ & $1.17 \pm 0.06$ & $0.90 \pm 0.03$ & * & $27.98 \pm 5.61$ & $35.12 \pm 2.80$ & NS \\
\hline 60 & $440.73 \pm 212.51$ & $80.86 \pm 39.71$ & * & $1.15 \pm 0.11$ & $0.95 \pm 0.02$ & * & $26.52 \pm 4.89$ & $37.50 \pm 3.82$ & NS \\
\hline 70 & $624.46 \pm 86.26$ & $68.73 \pm 20.21$ & $*$ & $1.15 \pm 0.08$ & $0.93 \pm 0.04$ & $*$ & $25.65 \pm 6.04$ & $33.61 \pm 3.18$ & NS \\
\hline 80 & $565.80 \pm 90.54$ & $92.86 \pm 18.94$ & * & $1.12 \pm 0.09$ & $0.89 \pm 0.02$ & $*$ & $25.39 \pm 3.25$ & $38.74 \pm 4.44$ & $*$ \\
\hline 90 & $582.93 \pm 26.07$ & $84.40 \pm 15.73$ & $*$ & $1.15 \pm 0.04$ & $0.93 \pm 0.06$ & $*$ & $25.94 \pm 3.25$ & $36.87 \pm 5.25$ & NS \\
\hline 100 & $595.44 \pm 26.50$ & $99.06 \pm 58.90$ & $*$ & $1.13 \pm 0.05$ & $0.90 \pm 0.05$ & * & $24.02 \pm 0.96$ & $38.03 \pm 2.56$ & $*$ \\
\hline All & $424.37 \pm 78.77$ & $91.90 \pm 14.17$ & $* *$ & $1.15 \pm 0.10$ & $0.94 \pm 0.07$ & $*$ & $26.46 \pm 7.12$ & $36.92 \pm 4.66$ & $*$ \\
\hline
\end{tabular}

The data for the deciduous dipterocarp forest (DDF) and mixed deciduous forest (MDF) were compared using $t$-tests. ${ }^{*} p<0.05,{ }^{* *} p<0.01$, and NS $=$ not significant.

species only occurred as seedlings and saplings along the edge-interior gradient in the DDF, e.g., Aporosa nigricans, Buchanania lanzan, Dipterocarpus obtusifolius, Lagerstroemia macrocarpa, Shorea siamensis, and Shorea obtusa. A few DDF species were able to regenerate along the edgeinterior gradient at the MDF sites, e.g., Strychnos nuxvomica, Quercus kerrii, and Mitragyna rotundifolia (Table 3). Nine of eleven MDF species were able to regenerate along the edge-interior gradient in the MDF, and many of these species were also able to regenerate at the DDF site, but at low densities (Table 3). A few species, such as Croton poilanei and Millettia brandisiana, only exhibited seedling and sapling regeneration at the MDF sites.

All six generalist species were able to regenerate along the edge-interior gradient of both the DDF and MDF sites. The seedling and sapling densities of five generalist species, e.g., Canarium subulatum, Colona flagrocarpa, Dalbergia cultrata, Pterocarpus macrocarpus, and Terminalia alata, did not significantly differ between the DDF and MDF sites. Only Vitex pinnata exhibited significantly higher densities of seedlings and saplings in the DDF compared to the MDF (Table 3). Mature trees of all six generalist species were also present at both the DDF and MDF sites (Table 2).

3.4. Factors Affecting Woody Tree Abundance. The final stress and instability values of the three-dimensional solution of the NMS ordination across the edge-interior gradients of the two forest types were 19.46 and 0.008 , respectively. All three physical environmental variables were strongly correlated with the first axis, but Dis was significantly correlated with the second axis (Table 4). Each species group (DDF, MDF, and generalist species) loaded along the NMS axes as clearly separate groups along gradients of the factor variables (PAR, SDb, SMC, and Dis; Figure 4). The PAR and SDb strongly affected the DDF species, such as Shorea obtusa (SHOB), Shorea siamensis (SHSI), Buchanania lanzan (BULA), Dalbergia oliveri (DAOL), Morinda coreia (MOCO), Lannea coromandelica (LACO), and Quercus kerrii (QUKE). The SMC strongly affected many MDF species, such as Tectona grandis
(TEGR), Xylia xylocarpa (XYXY), Dalbergia nigrescens (DANI), Phanera bracteata (PHBR), and Vitex canescens (VICA). However, some of the DDF species (Bombax anceps; BOAN) and generalist species (Colona flagrocarpa; COFL) were also strongly affected by SMC. The Dis strongly affected the spread of all species groups: generalist species such as Terminalia alata (TEAL), Canarium subulatum (CASU), and Pterocarpus macrocarpus (PTMA); DDF species such as Mitragyna rotundifolia (MIRO), Aporosa nigricans (APNI), and Dipterocarpus obtusifolius (DIOB); and MDF species such as Schleichera oleosa (SCOL) and Hymenodictyon orixense (HYOR).

3.5. Factors Determining Regeneration. The entire suite of environmental factors was categorized based on whether they were most related to the physical environment, recruitment limitation, or forest structure, and all factors appeared to be more important for DDF and MDF species regeneration than for generalist species (Table 5). The importance of each factor differed among species.

The regeneration of two DDF species, Aporosa nigricans and Shorea obtusa, was significantly positively affected by Dis and SMC $(p<0.01$ and $p<0.001$, respectively). The regeneration of Shorea obtusa was significantly negatively affected by forest structure (i.e., BA; $p<0.001$ ), while that of Strychnos nux-vomica was positively affected by BA $(p<0.01)$. The regeneration of only one DDF species was negatively affected by PAR, SDb, and TD (Table 5). The regeneration of four MDF species (Dalbergia nigrescens, Schleichera oleosa, Croton poilanei, and Vitex canescens) was significantly negatively affected by TD $(p<0.01$ or $p<0.001$ ), and two of these four species were also positively affected by BA $(p<0.01$ or $p<0.001)$. The regeneration of three MDF species (Dalbergia nigrescens, Schleichera oleosa, and Vitex canescens) was significantly positively affected by CD $(p<0.01$ or $p<0.001)$, and only the regeneration of Millettia brandisiana was significantly negatively affected by Dis $(p<0.05)$. The regeneration of three MDF species was negatively affected by SMC, and two species were significantly affected by PAR (Table 5). Only one species was 
Forest land

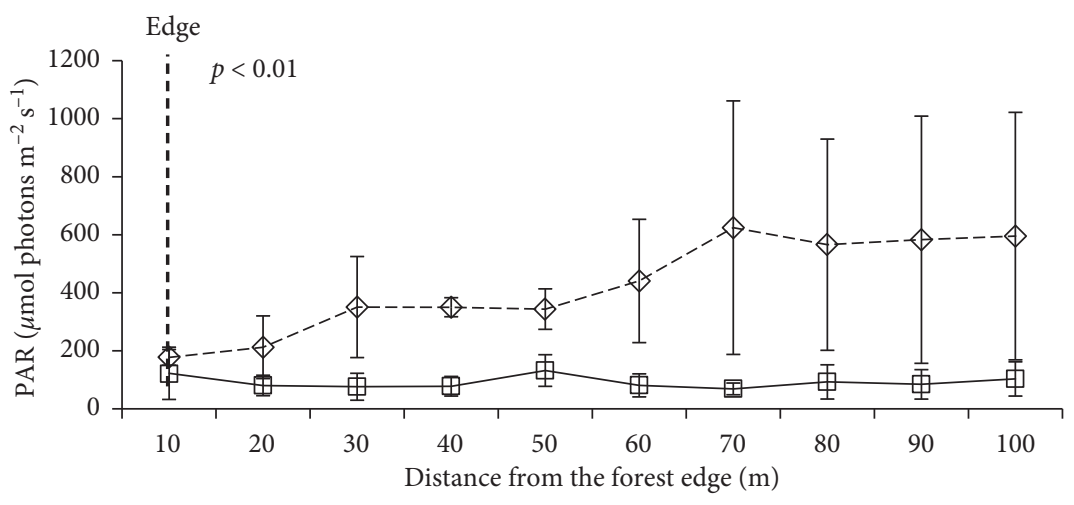

$--\diamond--\mathrm{DDF}$

$\square$ MDF

(a)

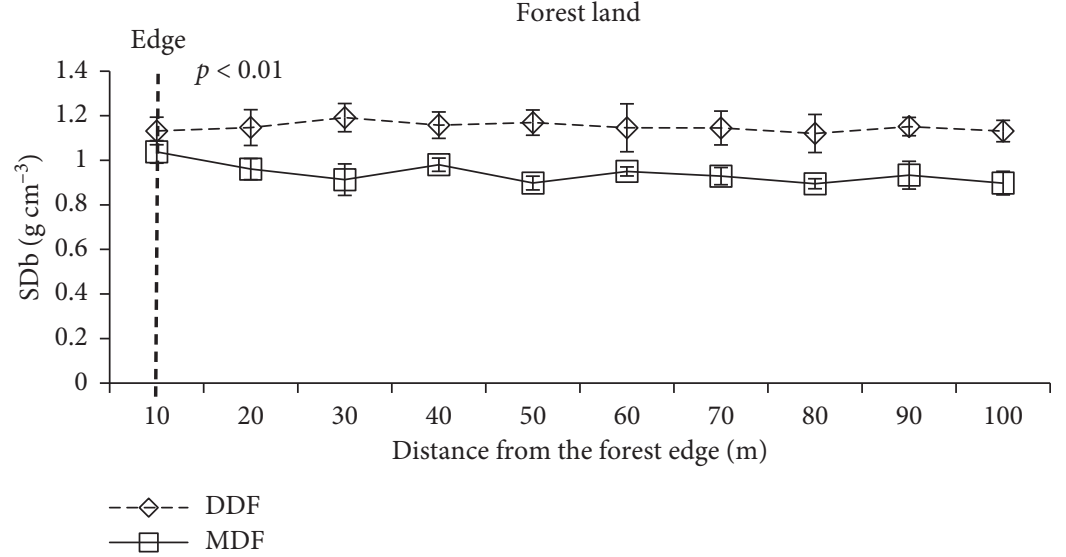

(b)

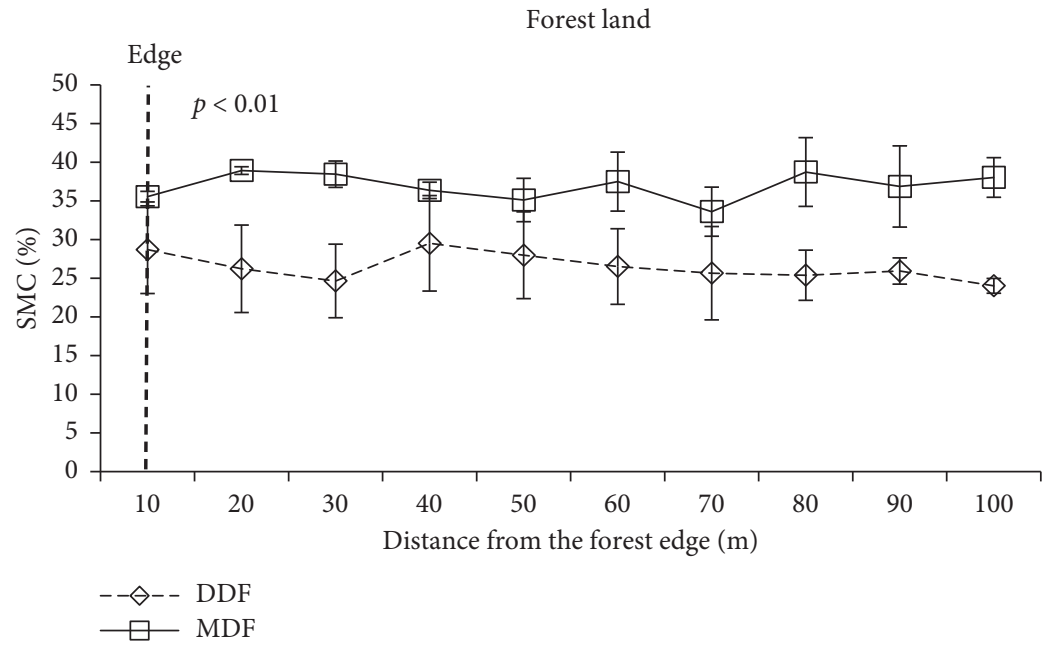

(c)

FIgURE 3: Changes in the physical environment from the edge to the interior of the forest study sites. (a) Photosynthetically active radiation (PAR) at $1.3 \mathrm{~m}$ above the ground, (b) soil bulk density (SDb), and (c) soil moisture content (SMC) measured in DDF and MDF in the Mae Khum Mee subwatershed. Mean \pm SD, $n=3$ (for both the DDF and MDF).

significantly affected by SDb $(p<0.001$; Table 5$)$. The regeneration of generalist species appeared to be less affected by the environmental factors of all three categories (physical environment, forest structure, and recruitment limitation)
(Table 5). The regeneration of two generalist species (Pterocarpus macrocarpus and Dalbergia cultrata) was significantly negatively affected by CD and SMC $(p<0.05$ or $p<0.001)$. The regeneration of Pterocarpus macrocarpus and 
TABle 2: Density (mean \pm standard deviation) of mature trees $(\mathrm{DBH} \geq 4.5 \mathrm{~cm})$ of each species in the deciduous dipterocarp forest (DDF) and mixed deciduous forest (MDF).

\begin{tabular}{|c|c|c|c|c|}
\hline No. & Species & $\begin{array}{c}\text { DDF } \\
\text { Mean } \pm \text { SD } \\
\left(\text { Stem } 0.01 \mathrm{ha}^{-1}\right)\end{array}$ & $\begin{array}{c}\text { MDF } \\
\text { Mean } \pm \text { SD } \\
\left(\text { Stem } 0.01 \mathrm{ha}^{-1}\right)\end{array}$ & Sig. \\
\hline \multicolumn{5}{|c|}{ Deciduous dipterocarp forest species } \\
\hline 1 & Shorea obtusa & $3.70 \pm 0.85$ & - & *** \\
\hline 2 & Shorea siamensis & $2.50 \pm 0.37$ & $0.03 \pm 0.03$ & *** \\
\hline 3 & Dipterocarpus obtusifolius & $0.43 \pm 0.16$ & - & *** \\
\hline 4 & Mitragyna rotundifolia & $0.43 \pm 0.13$ & $0.20 \pm 0.11$ & * \\
\hline 5 & Lannea coromandelica & $0.40 \pm 0.14$ & - & *** \\
\hline 6 & Aporosa nigricans & $0.27 \pm 0.13$ & $0.03 \pm 0.33$ & **** \\
\hline 7 & Dalbergia oliveri & $0.23 \pm 0.12$ & - & **** \\
\hline 8 & Strychnos nux-vomica & $0.17 \pm 0.11$ & - & *** \\
\hline 9 & Terminalia chebula & $17 \pm 0.10$ & - & *** \\
\hline 10 & Buchanania lanzan & $.17 \pm 0.08$ & - & **** \\
\hline 11 & Buchanania reticulata & $17 \pm 0.08$ & - & \\
\hline 12 & Quercus kerrii & $17 \pm 0.08$ & - & \\
\hline 13 & Bombax anceps & $13 \pm 0$ & $0.03 \pm 0.03$ & \\
\hline 14 & Morinda cor & $13 \pm 0$ & - & **** \\
\hline 15 & Symplocos racemosa & $0.10 \pm 0.07$ & - & *** \\
\hline 16 & $\begin{array}{c}\text { Lagerstroemia } \\
\text { macrocarpa }\end{array}$ & $0.10 \pm 0.06$ & - & \\
\hline 17 & Wendlandia tinctoria & $0.10 \pm 0.07$ & - & ** \\
\hline \multicolumn{5}{|c|}{ Mixed deciduous forest species } \\
\hline 1 & Phanera bracteata & - & $1.00 \pm 0.23$ & ${ }^{* * *}$ \\
\hline 2 & Xylia xylocarpa & $0.07 \pm 0.05$ & $.50 \pm 0.16$ & $* * *$ \\
\hline 3 & Schleichera oleosa & $0.17 \pm 0.10$ & $0.43 \pm 0.17$ & ** \\
\hline 4 & Millettia brandisiana & - & $0.40 \pm 0.15$ & *** \\
\hline 5 & Vitex canescens & - & $0.24 \pm 0.12$ & *** \\
\hline 6 & Tectona grandis & $0.07 \pm 0.07$ & $0.23 \pm 0.10$ & \\
\hline 7 & Dalbergia nigrescens & - & $0.20 \pm 0.12$ & *** \\
\hline 8 & Croton poilanei & - & $0.17 \pm 0.08$ & *** \\
\hline 9 & Hymenodictyon orixense & - & $0.17 \pm 0.08$ & \\
\hline 10 & Naringi crenulata & - & $0.10 \pm 0.07$ & \\
\hline 11 & Kydia calycina & - & $0.10 \pm 0.06$ & \\
\hline \multicolumn{5}{|c|}{ Generalist species } \\
\hline 1 & Pterocarpus macrocarpus & $2.00 \pm 0.42$ & $1.17 \pm 0.38$ & NS \\
\hline 2 & Vitex pinnata & $0.07 \pm 0.05$ & $0.07 \pm 0.05$ & NS \\
\hline 3 & Dalbergia cultrata & $0.33 \pm 0.14$ & $0.27 \pm 0.14$ & NS \\
\hline 4 & Colona flagrocarpa & $0.03 \pm 0.03$ & $0.10 \pm 0.07$ & NS \\
\hline 5 & Canarium subulatum & $0.17 \pm 0.10$ & $0.10 \pm 0.31$ & NS \\
\hline 6 & Terminalia alata & $0.20 \pm 0.09$ & $0.10 \pm 0.07$ & NS \\
\hline
\end{tabular}

The species classification is based on Mann-Whitney $U$ tests. ${ }^{*} p<0.05$, ${ }^{* *} p<0.01$, and ${ }^{* * *} p<0.001$

Vitex pinnata was positively affected by PAR $(p<0.05$ or $p<0.01)$. The regeneration of only one generalist species was positively affected by SDb $(p<0.001$; Table 5$)$.

\section{Discussion}

4.1. Colonization of Woody Species along the Edge-Interior Gradient. The numbers of seedlings, saplings, and mature trees observed at our sites allowed us to predict tree colonization success along the forest edge-interior gradient in both the DDF and MDF. Along the edge-interior gradient at the DDF sites, mature trees of DDF species high stem densities suggest successful colonization. These results suggest that canopy trees at the edge of the DDF are resistant to disturbances at forest edges, such as the environmental changes [24]. These environmental changes result from the increased disturbances that are common at forest edges, due to mechanisms such as increases in the rate of large tree loss and tree turnover [25]. More importantly, DDFs are firedependent, in that fires occur frequently and limit tree colonization. Annual, low-intensity fires of human origin are common in DDFs throughout Thailand [26] and these occur at particularly high frequencies in edge areas [27]. Mature trees of DDF species such as Shorea obtusa, Shorea siamensis, Dipterocarpus obtusifolius, and Quercus kerrii exhibit adaptations to fire, such as thicker bark for wildfire resilience [28]. In addition, DDF canopy trees, such as Shorea obtusa, Shorea siamensis, and Dipterocarpus obtusifolius, are not commonly harvested for timber (i.e., for construction purposes) in northern Thailand; consequently, illegal logging by local residents occurs less frequently. Combined, the above factors have likely contributed to the persistence of mature trees of DDF species within the edge areas of DDFs. Low densities of saplings and seedlings at frequently burned sites (i.e., forest edges) indicate that frequent fires can inhibit successful tree regeneration [29]. However, Stott [28] reported that low-intensity fires promoted the recovery of Shorea obtusa seedlings. Only Mitragyna rotundifolia seedlings and saplings were able to regenerate within the edge area of the MDF sites. These results confirm that DDF species are best adapted to the conditions along the edgeinterior gradient within DDFs; thus, colonization in different forest types is limited.

Along the edge-interior gradient of the MDF sites, the colonization of mature trees of MDF species with low stem densities was unsuccessful. Tree mortality is one of the most important biological consequences of edge effects [8], particularly for large trees, which are disproportionately susceptible to wind turbulence and physiological stresses [25]. Moreover, canopy trees may be subject to illegal logging by residents; indeed, dominant MDF species, such as Tectona grandis and Xylia xylocarpa, are sought after for timber in northern Thailand [30]. For example, teak (Tectona grandis) is one of the most valuable tree species and was consequently designated a priority logging species [31]. Many edge areas of MDFs have suffered from illegal logging, slash-and-burn agriculture, and other disturbances, all of which have degraded native teak forests in northern Thailand [32]. As a result, some edge areas of MDFs have been invaded by secondary successional species via seed rain and soil seed bank germination. Saplings and seedlings that can regenerate in areas farther from edges are usually those adapted to edge microclimates and are often late successional species [33]. Our results suggest that many of the MDF species that regenerated along the edge-interior gradient at the DDF sites were only able to do so during the sapling and seedling stages, and colonization was unsuccessful during maturity. Wildfire occurs frequently at the study sites every year, caused by farmers burning corn stumps after harvest in the dry season [18]. Fire disturbances are important factors affecting the dynamics and regeneration of tropical dry deciduous forests [34]. The seedling survival of deciduous forest species is strongly affected by light conditions during the rainy season and resistance to fire during the subsequent dry season [35]. In the DDFs, forest fires occurred at higher frequencies than 
TABLE 3: Mean \pm standard deviation of the total stem density of seedlings (in $4 \times 4 \mathrm{~m}$ subplots) and saplings (in $10 \times 10 \mathrm{~m}$ quadrats), sampled from locations at the same position along each belt plot inside the deciduous dipterocarp forest (DDF) and mixed deciduous forest (MDF).

\begin{tabular}{|c|c|c|c|c|}
\hline No. & Species & $\begin{array}{c}\text { DDF } \\
\text { Mean } \pm \text { SD } \\
\left(\text { Stem } 0.0116 \mathrm{ha}^{-1}\right)\end{array}$ & $\begin{array}{c}\text { MDF } \\
\text { Mean } \pm \text { SD } \\
\left(\text { Stem } 0.0116 \mathrm{ha}^{-1}\right)\end{array}$ & Sig. \\
\hline \multicolumn{5}{|c|}{ Deciduous dipterocarp forest species } \\
\hline 1 & Shorea obtusa & $3.97 \pm 1.51$ & - & $* * *$ \\
\hline 2 & Shorea siamensis & $0.70 \pm 0.23$ & - & $* * *$ \\
\hline 3 & Dipterocarpus obtusifolius & $0.30 \pm 0.24$ & - & $*$ \\
\hline 4 & Mitragyna rotundifolia & $1.67 \pm 0.66$ & $1.17 \pm 0.68$ & NS \\
\hline 5 & Lannea coromandelica & $0.30 \pm 0.15$ & - & *** \\
\hline 6 & Aporosa nigricans & $1.77 \pm 0.80$ & - & $* * *$ \\
\hline 7 & Dalbergia oliveri & $0.53 \pm 0.27$ & - & $* * *$ \\
\hline 8 & Strychnos nux-vomica & $0.97 \pm 0.38$ & $0.23 \pm 0.23$ & $* *$ \\
\hline 9 & Buchanania reticulata & $0.77 \pm 0.27$ & - & *** \\
\hline 10 & Quercus kerrii & $0.23 \pm 0.17$ & $0.03 \pm 0.03$ & $*$ \\
\hline 11 & Lagerstroemia macrocarpa & $0.17 \pm 0.10$ & - & NS \\
\hline 12 & Wendlandia tinctoria & $0.50 \pm 0.35$ & - & ** \\
\hline \multicolumn{5}{|c|}{ Mixed deciduous forest species } \\
\hline 1 & Phanera bracteata & $0.23 \pm 0.12$ & $0.60 \pm 0.23$ & $*$ \\
\hline 2 & Xylia xylocarpa & $0.20 \pm 0.17$ & $1.03 \pm 0.27$ & *** \\
\hline 3 & Schleichera oleosa & $0.67 \pm 0.48$ & $0.60 \pm 0.19$ & NS \\
\hline 4 & Millettia brandisiana & - & $1.17 \pm 0.33$ & $* * *$ \\
\hline 5 & Vitex canescens & $0.23 \pm 0.11$ & $0.70 \pm 0.2$ & $* * *$ \\
\hline 6 & Tectona grandis & $0.13 \pm 0.10$ & $0.47 \pm 0.13$ & $* *$ \\
\hline 7 & Dalbergia nigrescens & $0.33 \pm 0.21$ & $0.60 \pm 0.16$ & $*$ \\
\hline 8 & Croton poilanei & - & $2.43 \pm 1.14$ & $* * *$ \\
\hline 9 & Hymenodictyon orixense & $0.10 \pm 0.06$ & $0.73 \pm 0.29$ & $* * *$ \\
\hline \multicolumn{5}{|c|}{ Generalist species } \\
\hline 1 & Pterocarpus macrocarpus & $2.73 \pm 0.66$ & $1.55 \pm 0.33$ & NS \\
\hline 2 & Vitex pinnata & $0.80 \pm 0.31$ & $0.13 \pm 0.08$ & ** \\
\hline 3 & Dalbergia cultrata & $2.07 \pm 0.45$ & $1.20 \pm 0.39$ & NS \\
\hline 4 & Colona flagrocarpa & $1.10 \pm 0.35$ & $0.83 \pm 0.29$ & NS \\
\hline 5 & Canarium subulatum & $0.10 \pm 0.07$ & $0.23 \pm 0.14$ & NS \\
\hline 6 & Terminalia alata & $0.07 \pm 0.07$ & $0.47 \pm 0.47$ & NS \\
\hline
\end{tabular}

Forest types were compared using the Mann-Whitney $U$ test. ${ }^{*} p<0.05,{ }^{*} p<0.01$, and ${ }^{* * *} p<0.001$.

TABLE 4: Spearman's rank correlations between the physical factors of photosynthetically active radiation (PAR), soil moisture content (SMC), and soil bulk density (SDb), and distance from the edge to the forest interior (Dis), and nonmetric multidimensional scaling (NMS) ordination axes for mature trees along the edge-interior gradients of both dry deciduous forest and mixed deciduous forest edge sites in the Mae Khum Mee subwatershed.

\begin{tabular}{lccc}
\hline Environmental variable & NMS1 & NMS2 & NMS3 \\
\hline PAR $\left(\mu \mathrm{mol}_{\left.\text {photons } \mathrm{m}^{-2} \mathrm{~s}^{-1}\right)}\right.$ & $0.788^{* *}$ & -0.133 & 0.101 \\
SDb $\left(\mathrm{g} \mathrm{cm}^{-3}\right)$ & $0.950^{* *}$ & 0.020 & 0.033 \\
SMC $(\%)$ & $-0.880^{* *}$ & -0.224 & 0.089 \\
Dis $(\mathrm{m})$ & 0.107 & $-0.625^{*}$ & 0.200 \\
\hline
\end{tabular}

${ }^{*} p<0.05$ and ${ }^{* *} p<0.01$.

in the MDFs [36]. This increased exposure to fire likely caused high mortality of the seedlings and saplings of MDF species during the dry season [35], as these species have low fire resistance (i.e., resprouting ability) compared with DDF species [29].

All stages of the generalist species (mature, saplings, and seedlings) were able to colonize the edge-interior gradients of both DDFs and MDFs, which suggests that generalist species had characteristics of early successional species (i.e., growing in newly disturbed sites) and were affected by disturbance intensity and type (e.g., wildfire and clear-cutting) [37]. Ecological specialists (i.e., DDF and MDF species) are expected to benefit from environments that are relatively homogeneous (in space and time), whereas generalist species should benefit from environments that are heterogeneous [38]. Generalist species use various habitat types within the landscape matrix and would therefore be less affected by habitat fragmentation [39]. For example, in Thailand, Pterocarpus macrocarpus (a generalist species) is dominant in secondary deciduous forests $[40,41]$, and in the present study, it was a dominant species in both primary DDFs and MDFs. However, the edges surrounding any given restoration area are more likely to be secondary forest than primary forest.

4.2. Factors Determining Woody Species Colonization. The canopies of deciduous forests are more open than those of rain forests, and leaf shedding during the dry season increases canopy opening [42]. Consequently, gradients of forest-edge microclimates are expected to be less heterogeneous in dry forests than in rain forests, perhaps leading to more moderate effects on resident species. In addition, 


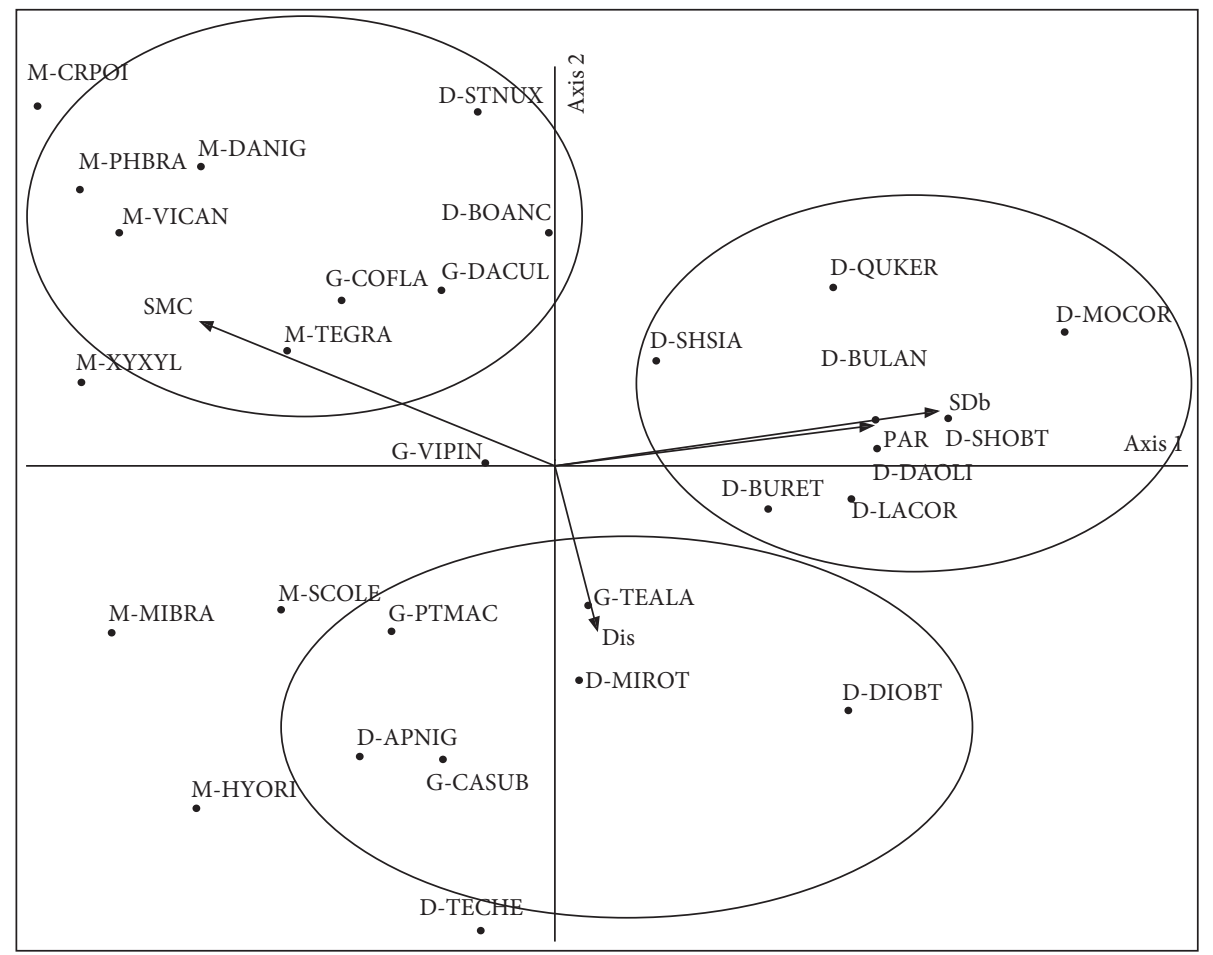

FIgURE 4: Nonmetric multidimensional scaling (NMS) ordination diagram of the distance from the edge to the forest interior (Dis, $\mathrm{m}$ ), and the physical environmental variables (SMC, \%; PAR, $\mu \mathrm{mol}$ photons $\mathrm{m}^{-2} \mathrm{~s}^{-1}$; $\mathrm{SDb}, \mathrm{g} \mathrm{cm}^{-3}$ ) affecting the distribution of woody tree species (DDF species (D), MDF species (M), and generalist species $(G)$ ) along the edge-interior gradients of different forest types (DDF and MDF) in the Mae Khum Mee subwatershed, Phrae Province.

TABLE 5: Significant factors in the generalized linear mixed models of species with $\geq 30$ stems, selected to minimize Akaike's information criterion. The variables included physical environmental factors (photosynthetically active radiation (PAR, $\mu \mathrm{mol} \mathrm{photons} \mathrm{m}^{-2} \mathrm{~s}^{-1}$ ) at $1.3 \mathrm{~m}$ above the ground, soil moisture content (SMC, \%), soil bulk density (SDb, $\left.\mathrm{g} \mathrm{cm}^{-3}\right)$ ), factors related to forest structure (basal area (BA, $\mathrm{m}^{2} \mathrm{ha}^{-1}$ ), mature tree density $\left(\mathrm{TD}\right.$, stem $\left.\mathrm{ha}^{-1}\right)$ ), and recruitment factors (distance from the edge to the forest interior (Dis, $\mathrm{m}$ ), conspecific adult density (CD, stem $\left.0.01 \mathrm{ha}^{-1}\right)$ ).

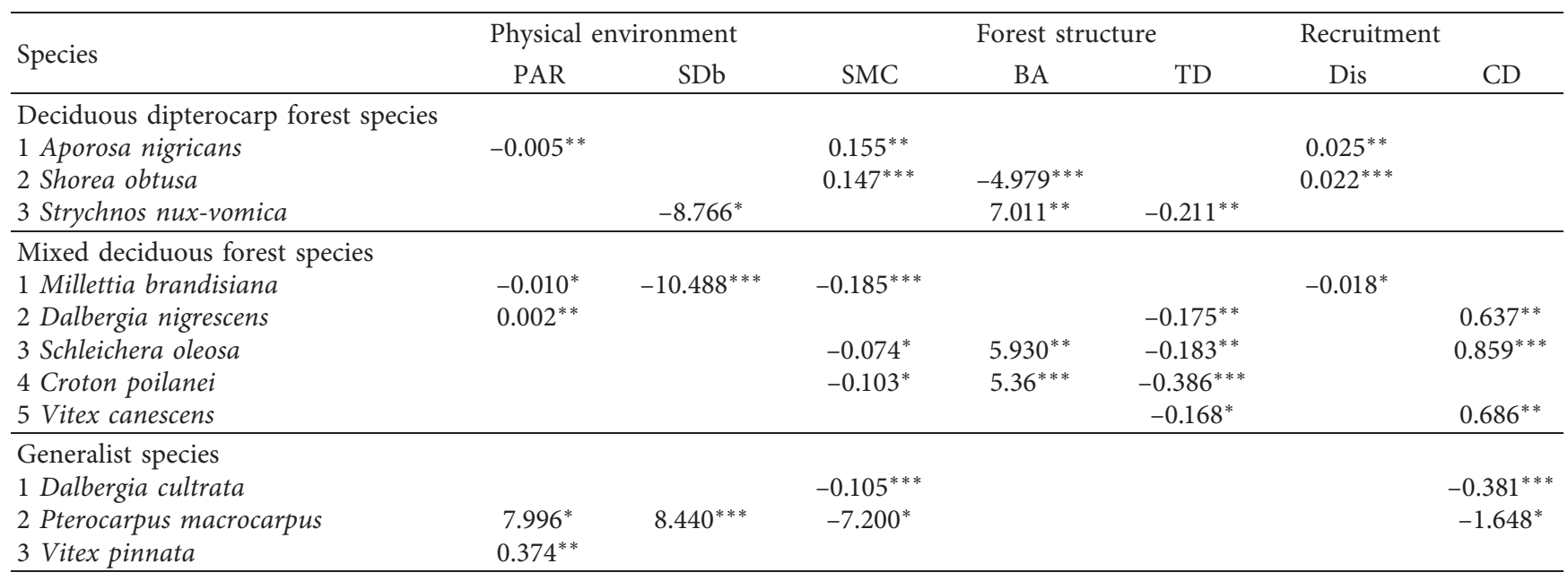

${ }^{*} p<0.05,{ }^{* *} p<0.01$, and ${ }^{* * *} p<0.001$.

species that are strongly affected by fragmentation may occur less frequently within the reduced species pool of dry forests [43]. In this study, the colonization rates of mature trees of DDF species were strongly positively affected by PAR and SDb and negatively affected by humid soil. These results suggest that the canopy trees of DDFs are better able to establish under extreme drought conditions (i.e., high light intensity and dry and dense soil). The species composition of DDFs was characterized by low stem densities of deciduous species, which promoted high light conditions at 
the forest floor and thus drier soil during the dry season [35]. Deciduous dipterocarp forests also experience stronger effects of fire, which is promoted by the increased soil erosion and soil density within the region [29]. Based on soil properties, we propose the following mechanism to explain the current vegetative composition that became once the original vegetation was destroyed [2]. The extremely dry soil conditions currently found in the DDFs are not an intrinsic property of forest soil; instead, this environment is generated by the high light conditions created by leaf habit and a deciduous life history [44], as well as the removal of the original vegetation [2].

Most of the determining factors, i.e., physical factors, forest structure, and recruitment limitation, strongly affected the colonization of saplings and seedlings of DDF species, suggesting that these species are critical early colonizers of forest-edge habitats. Humid soils appear to favor the colonization of saplings and seedlings of DDF species; however, such conditions are rare along the edge-interior gradient of DDFs, due to frequent drought conditions created by leaf shedding and high light intensity at the forest floor, which facilitates the evaporation of soil moisture [45]. The colonization of saplings and seedlings of DDF species was also limited by the Dis; areas close to the edge are typically highly disturbed, suggesting that the colonization of saplings and seedlings was determined by site limitation [13]. The edge effects associated with habitat fragmentation are a structurally dissimilar matrix and associated with changes in environmental conditions [46]. The microclimate at the forest edge differs from that of the forest interior, particularly in incident light and humidity [46]. Such environmental shifts cause changes in the abundance and distribution of species, either as a direct result of altered physical conditions or indirectly via the physiological tolerances of species to conditions at and near the edge (i.e., higher light levels, wind exposure, higher temperatures, and lower humidity) [9]. These findings indicate that the seedlings and saplings of DDF species are unable to colonize areas near forest edges, and do not develop to maturity.

The colonization rates of mature trees of MDF species were strongly positively affected by humid soil. Indeed, the SMCs at the MDF sites were higher than at the DDF sites. Typically, the content of clay-sized particles in the soil of the MDFs is higher than in the DDFs, resulting in increased moisture retention in the MDF soil [47]. The SMC is also higher under more woody vegetation (i.e., a dense canopy) compared with forests with less woody vegetation (i.e., an open canopy), due to the positive effects of shading by the canopy. Thus, the cooler below-canopy temperatures results in a higher relative humidity inside the forest, assuming a constant absolute air water content. An additional impact of soil on the forest microclimate results from evaporative cooling or the latent heat flux [48]. The observed lower SDb in the MDFs was likely due to the greater amount of organic matter derived from the minimally decomposed humus of the more diverse tree species within the MDFs.

The colonization rates of the saplings and seedlings of MDF species were primarily determined by dry soils and sparse TD, suggesting that juvenile MDF species can successfully establish under edge conditions. The canopy gaps associated with the sparse TD along the edge fosters direct sunlight, in turn affecting both soil and air temperature; the direct effect on air temperature is assumed to be larger, as the air is partially mixed and exchanged with open areas (exterior). Consequently, the forest soils generally warm more than the in the forest interior [48]. Most MDF species also experienced limited colonization by conspecific adult trees, suggesting seed limitation at the MDF site [13]. The mother trees are required for successful establishment. Natural regeneration is the least expensive approach to the rehabilitation of degraded areas, as long as prior disturbances left residual colonization sources (e.g., soil seed banks, mother trees, and sprouts) that could serve as succession primers [49]. The transition from the edge to interior in fragmented areas may depend upon newly arrived fresh seeds from mother trees [50]. For example, MDF species such as Tectona grandis and Xylia xylocarpa are dispersed by gravity and are dispersed close to the mother tree [30]. However, the canopy trees of the MDFs experience high rates of illegal logging by local people, particularly in edge areas. In the developing countries of Asia, MDFs are more often illegally disturbed compared with other forest types [51], because their fertile soil promotes high abundances of dominant species that are also economically valuable (i.e., Tectona grandis and Xylia xylocarpa) [30, 41]. These factors contribute to the relatively low colonization rates of some MDF species within edge habitats.

The colonization of mature trees of generalist species appeared to be much less affected by the factors limiting the colonization of DDF and MDF species. This confirmed why generalist species establish so successfully in both DDFs and MDFs. By definition, generalist species are able to thrive under a wide array of environmental conditions and can utilize a variety of different resources [52]. Generalists also play critical roles in ecosystem functioning and should be incorporated into conservation and monitoring programs. Because generalists are resilient to population declines, the conservation of generalists to promote biodiversity depends on maintaining a connected forest landscape with a mosaic of plants at different successional stages [52]. Our results indicated that the colonization of saplings and seedlings of generalist species was positively affected by high light and dry soil and negatively affected by the density of conspecific adult trees, suggesting that these species can successfully establish under conditions characteristic of forest edges [9]. Therefore, generalist species appear to follow community assembly rules, particularly in habitats where communities are subjected to varying levels of disturbance [53]. Therefore, forest-edge restoration efforts should incorporate generalist species, as the distinction between generalist and specialist species can help to pinpoint general mechanisms of species filtering, similar to approaches using species traits rather than the species themselves.

4.3. Implications for Deciduous Forest-Edge Management. We found that DDF and MDF species experienced difficulty in colonizing edge habitats within both DDFs and MDFs, 
primarily due to recruitment limitations, the physical environment, and factors related to forest structure. The colonization of saplings and seedlings of DDF species was determined by humid soil in areas farther along the edgeinterior gradient, whereas mature trees exhibited high abundance on dry soil. The colonization of saplings and seedlings of MDF species was negatively affected by dry soil and low stem density but positively affected by the density of conspecific adult trees; however, mature trees were abundant on humid soil and experienced more frequent disturbance from illegal logging. Thus, reducing detrimental environmental factors and recruitment limitation (i.e., seed and site limitations) is required for the rapid restoration of DDF and MDF species along forest edges. The first step toward the rapid recovery of forests is to consider capitalizing upon the natural regeneration of generalist species, such as Pterocarpus macrocarpus, Dalbergia cultrata, Vitex pinnata, Canarium subulatum, Colona flagrocarpa, and Terminalia alata. They experience substantially fewer recruitment limitations when compared with MDF and DDF species. These generalist species are better able to regenerate under high light conditions and/or low soil moisture, and they require fewer conspecific adult trees; such conditions are specific to forest-edge habitats. Planting species-enrichment initiatives in areas close to forest edges may facilitate the restoration of DDF and MDF ecosystems, primarily because the successful establishment of generalist species within edge areas will positively affect forest community composition and the physical environment, allowing the system to more closely resemble primary forest over time [15]. Such conditions would facilitate the regeneration of both DDF and MDF species, which have difficultly regenerating in such areas. However, seed recruitment limitation may still occur and may require planted species enrichment up to $100 \mathrm{~m}$ from the forest edge into the forest interior, to promote species colonization and accelerate the restoration process.

\section{Data Availability}

The data supporting the findings of this study, and the funding details, are held by The Biodiversity-based Economy Development Office of Thailand. These data, which were used under license for the current study, are not publicly available. However, the data are available from the corresponding author upon reasonable request and with permission from The Biodiversity-based Economy Development Office.

\section{Conflicts of Interest}

The authors declare that there are no conflicts of interest regarding the publication of this paper.

\section{Acknowledgments}

This research was made possible by the assistance of students from the Department of Agroforestry, Phrae Campus, Maejo University. The authors thank the academic and research staff of Phrae Campus for allowing them to conduct this study. This study was supported by funds provided by The
Biodiversity-based Economy Development (contract number BEDO.-NRCT. 21/2017).

\section{References}

[1] R. L. Chazdon, C. A. Harvey, M. Martínez-ramos et al., "Seasonally dry tropical forest biodiversity and conservation value in agricultural landscapes of mesoamerica," in Seasonally Dry Tropical Forests: Ecology and Conservation, pp. 195-219, Springer, Switzerland, 2005.

[2] K. Sakurai, S. Tanaka, S. Ishiduka, and M. Kanzaki, "Differences in soil properties of dry evergreen and dry deciduous forests in the Sakaerat environmental research station," Tropics, vol. 8, no. 1/2, pp. 61-80, 1998.

[3] D. Kanzaki, U. Kutintara, C. Yarwudhi, H. Tanaka, and T. Nakashisuka, "Structural dynamics of a natural mixed deciduous forest in western Thailand," Journal of Vegetation Science, vol. 10, no. 6, pp. 777-786, 1999.

[4] K. Wanthongchai, J. Bauhus, and J. G. Goldammer, "Nutrient losses through prescribed burning of aboveground litter and understorey in dry dipterocarp forests of different fire history," Catena, vol. 74, no. 3, pp. 321-332, 2008.

[5] C. O. Delang, "Deforestation in northern Thailand: the result of Hmong farming practices or Thai development strategies?" Society \& Natural Resources, vol. 15, no. 6, pp. 483-501, 2002.

[6] S. Sloan and J. A. Sayer, "Forest Resources Assessment of 2015 shows positive global trends but forest loss and degradation persist in poor tropical countries," Forest Ecology and Management, vol. 352, pp. 134-145, 2015.

[7] N. S. Sodhi, L. P. Koh, R. Clements et al., "Conserving Southeast Asian forest biodiversity in human-modified landscapes," Biological Conservation, vol. 143, no. 10, pp. 2375-2384, 2010.

[8] W. F. Laurance, H. E. M. Nascimento, S. G. Laurance et al., "Habitat fragmentation, variable edge effects, and the Landscape-Divergence Hypothesis," PLoS One, vol. 2, Article ID e1017, 2007.

[9] C. Murcia, "Edge effects in fragmented forests: implications for conservation," Trends in Ecology \& Evolution, vol. 10, no. 2, pp. 58-62, 1995.

[10] M. Oosterhoorn and M. Kappelle, "Vegetation structure and composition along an interior-edge-exterior gradient in a Costa Rican montane cloud forest," Forest Ecology and Management, vol. 126, no. 3, pp. 291-307, 2000.

[11] T. D. Heithecker and C. B. Halpern, "Edge-related gradients in microclimate in forest aggregates following structural retention harvests in western Washington," Forest Ecology and Management, vol. 248, no. 3, pp. 163-173, 2007.

[12] H. Asbjornsen, M. S. Ashton, D. J. Vogt, and S. Palacios, "Effects of habitat fragmentation on the buffering capacity of edge environments in a seasonally dry tropical oak forest ecosystem in Oaxaca, Mexico," Agriculture, Ecosystems \& Environment, vol. 103, no. 3, pp. 481-495, 2004.

[13] M. R. Piana, M. F. Aronson, S. T. Pickett, and S. N. Handel, "Plants in the city: understanding recruitment dynamics in urban landscapes," Frontiers in Ecology and the Environment, vol. 17, no. 8, pp. 455-463, 2019.

[14] F. P. L. De Melo, R. Dirzo, and M. Tabarelli, "Biased seed rain in forest edges: evidence from the Brazilian Atlantic forest," Biological Conservation, vol. 132, no. 1, pp. 50-60, 2006.

[15] R. L. Chazdon, C. A. Peres, D. Dent et al., "The Potential for species conservation in tropical secondary forests," Conservation Biology, vol. 23, no. 6, pp. 1406-1417, 2009. 
[16] S. Choenkwan, J. M. Fox, and A. T. Rambo, "Agriculture in the mountains of Northeastern Thailand: current situation and prospects for development," Mountain Research and Development, vol. 34, no. 2, pp. 95-106, 2014.

[17] L. Asanok and T. Lutteerasuwan, "Tree species composition of plant community in Mae Khum mee watershed, Phrae province," Thai Forest Ecological Reserch, vol. 1, pp. 19-27, 2016.

[18] GISTDA, Thailand Fire Monitoring System, Ministry of Natural Resources and Environment, Bangkok, Thailand, 2019.

[19] S. Fraver, "Vegetation responses along edge-to-Interior gradients in the mixed Hardwood forests of the Roanoke river basin, North Carolina," Conservation Biology, vol. 8, no. 3, pp. 822-832, 1994

[20] S. Jose, A. R. Gillespie, S. J. George, and B. M. Kumar, "Vegetation responses along edge-to-interior gradients in a high altitude tropical forest in peninsular India," Forest Ecology and Management, vol. 87, no. 1-3, pp. 51-62, 1996.

[21] R. Pooma and S. Suddee, Thai Plant Names Tem Smitinand, Office of the Forest Herbarium, Department of National Park, Wildlife and Plant Conservation, Bangkok, Thailand, 2014.

[22] A. Baddeley, A. Hardegen, T. Lawrence, R. K. Milne, G. Nair, and S. Rakshit, "On two-stage Monte Carlo tests of composite hypotheses," Computational Statistics \& Data Analysis, vol. 114, pp. 75-87, 2017.

[23] H. Ogasawara, "Bias correction of the Akaike information criterion in factor analysis," Journal of Multivariate Analysis, vol. 149 , pp. 144-159, 2016.

[24] M. J. Campbell, W. Edwards, A. Magrach et al., "Forest edge disturbance increases rattan abundance in tropical rain forest fragments," Scientific Reports, vol. 7, no. 1, Article ID 6071, 2017.

[25] C. Wekesa, E. K. Maranga, B. K. Kirui, G. M. Muturi, and M. Gathara, "Interactions between native tree species and environmental variables along forest edge-interior gradient in fragmented forest patches of Taita Hills, Kenya," Forest Ecology and Management, vol. 409, pp. 789-798, 2018.

[26] D. Marod and U. Kutintara, Forest Ecology, Forest Biology Department, Facultly of Forestry, Kasetsart University, Bangkok, Thailand, 2011.

[27] I. Numata, S. S. Silva, M. A. Cochrane, and M. V. N. d'Oliveira, "Fire and edge effects in a fragmented tropical forest landscape in the southwestern Amazon," Forest Ecology and Management, vol. 401, pp. 135-146, 2017.

[28] P. Stott, "The Spatial pattern of dry season fires in the savanna forests of Thailand," Journal of Biogeography, vol. 13, no. 4, pp. 345-358, 1986.

[29] K. Wanthongchai, J. G. Goldammer, and J. Bauhus, "Effects of fire frequency on prescribed fire behaviour and soil temperatures in dry dipterocarp forests," International Journal of Wildland Fire, vol. 20, no. 1, pp. 35-45, 2011.

[30] N. Koonkhunthod, K. Sakurai, and S. Tanaka, "Composition and diversity of woody regeneration in a 37-year-old teak (Tectona grandis L.) plantation in Northern Thailand," Forest Ecology and Management, vol. 247, no. 1-3, pp. 246-254, 2007.

[31] A. Auykim, K. Duangsathaporn, and P. Prasomsin, "Growth of teak regenerated by coppice and stump planting in Mae Moh plantation, Lampang province, Thailand," Agriculture and Natural Resources, vol. 51, no. 4, pp. 273-277, 2017.

[32] P. Kaewkrom, J. Gajaseni, C. F. Jordan, and N. Gajaseni, "Floristic regeneration in five types of teak plantations in
Thailand," Forest Ecology and Management, vol. 210, no. 1-3, pp. 351-361, 2005.

[33] A. Dupuch and D. Fortin, "The extent of edge effects increases during post-harvesting forest succession," Biological Conservation, vol. 162, pp. 9-16, 2013.

[34] S. Bunyavejchewin, P. J. Baker, and S. J. Davies, "Seasonally dry tropical forest in Continental Southeast Asia structure, composition, and dynamics,", in The Ecology and Conservation of Seasonally Dry Forest in Asia, Smithsonian Institution Scholarly Press, Washington, DC, USA, 2011.

[35] D. Marod, U. Kutintara, H. Tanaka, and T. Nakashizuka, "Effects of drought and fire on seedling survival and growth under contrasting light conditions in a seasonal tropical forest," Journal of Vegetation Science, vol. 15, no. 5, pp. 691-700, 2004.

[36] K. Wiriya and S. Kaitpraneet, "Fire behavior in dry deciduous dipterocarp forest at Huai Kha Khaeng Wildlife Sanctuary, Uthai Thani province," Kasetsart Journal (Natural Science), vol. 47, pp. 41-47, 2009.

[37] D. B. Lindenmayer, M. J. Westgate, B. C. Scheele, C. N. Foster, and D. P. Blair, "Key perspectives on early successional forests subject to stand-replacing disturbances," Forest Ecology and Management, vol. 454, p. 117656, 2019.

[38] M. Marvier, P. Kareiva, and M. G. Neubert, "Habitat destruction, fragmentation, and disturbance promote invasion by habitat generalists in a multispecies metapopulation," Risk Analysis, vol. 24, no. 4, pp. 869-878, 2004.

[39] C. Brouat, H. Chevallier, S. Meusnier, T. Noblecourt, and J.-Y. Rasplus, "Specialization and habitat: spatial and environmental effects on abundance and genetic diversity of forest generalist and specialist Carabus species," Molecular Ecology, vol. 13, no. 7, pp. 1815-1826, 2004.

[40] K. Kamo, T. Vacharangkura, S. Tiyanon, C. Viriyabuncha, S. Nimpila, and B. Doangsrisen, "Plant species diversity in tropical planted forests and implication for restoration of forest ecosystems in Sakaerat, Northeastern Thailand," Japan Agricultural Research Quarterly: JARQ, vol. 36, no. 2, pp. 111-118, 2002.

[41] P. Kaewkrom, N. Kaewkla, S. Thummikkapong, and S. Punsang, "Evaluation of carbon storage in soil and plant biomass of primary and secondary mixed deciduous forests in the lower northern part of Thailand," African Journal of Environmental Science and Technology, vol. 5, pp. 8-14, 2011.

[42] D. L. M. Vieira, A. Scariot, A. B. Sampaio, and K. D. Holl, "Tropical dry-forest regeneration from root suckers in Central Brazil," Journal of Tropical Ecology, vol. 22, no. 3, pp. 353-357, 2006.

[43] A. B. Holl and A. Scariot, "Efeito de borda na diversidade, composição e estrutura da comunidade arbórea em uma floresta estacional decidual no Brasil Central," Revista Árvore, vol. 35, no. 5, pp. 1121-1134, 2011.

[44] A. Ishida, S. Diloksumpun, P. Ladpala et al., "Contrasting seasonal leaf habits of canopy trees between tropical drydeciduous and evergreen forests in Thailand," Tree Physiology, vol. 26, no. 5, pp. 643-656, 2006.

[45] Y. Ma, R. L. Van Dam, and D. H. Jayawickreme, "Soil moisture variability in a temperate deciduous forest: insights from electrical resistivity and throughfall data," Environmental Earth Sciences, vol. 72, no. 5, pp. 1367-1381, 2014.

[46] W. F. Laurance, J. L. C. Camargo, R. C. C. Luizão et al., "The fate of Amazonian forest fragments: a 32-year investigation," Biological Conservation, vol. 144, no. 1, pp. 56-67, 2011.

[47] K. K. Myo, S. Thwin, and N. Khaing, "Floristic composition, structure and soil properties of mixed deciduous forest and 
deciduous dipterocarp forest: case study in Madan Watershed, Myanmar," American Journal of Plant Sciences, vol. 7, no. 2, pp. 279-287, 2016.

[48] G. Arx, E. G. V. Pannatier, A. Thimonier, and M. Rebetez, "Microclimate in forests with varying leaf area index and soil moisture: potential implications for seedling establishment in a changing climate," Journal of Ecology, vol. 101, no. 5, pp. 1201-1213, 2013.

[49] H. Yue, W. Shao, J. Jiang, X. Li, and S. Sun, "Ecological succession of a natural community of Castanopsis sclerophylla on Laoshan Island, China," Journal of Forestry Research, vol. 27, no. 5, pp. 1171-1176, 2016.

[50] M. Schmidt, H. Jochheim, K.-C. Kersebaum, G. Lischeid, and C. Nendel, "Gradients of microclimate, carbon and nitrogen in transition zones of fragmented landscapes-a review," $A g$ ricultural and Forest Meteorology, vol. 232, pp. 659-671, 2017.

[51] G. Mandal and S. P. Joshi, "Analysis of vegetation dynamics and phytodiversity from three dry deciduous forests of Doon Valley, Western Himalaya, India," Journal of Asia-Pacific Biodiversity, vol. 7, no. 3, pp. 292-304, 2014.

[52] V. Devictor, R. Julliard, and F. Jiguet, "Distribution of specialist and generalist species along spatial gradients of habitat disturbance and fragmentation," Oikos, vol. 117, no. 4, pp. 507-514, 2008.

[53] Z. Lososová, M. Chytrý, S. Cimalová et al., "Weed vegetation of arable land in Central Europe: gradients of diversity and species composition," Journal of Vegetation Science, vol. 15, no. 3, pp. 415-422, 2004. 